JURNAL LENSA PENDAS

Volume 5 Nomor 2 Tahun 2020, Hlm 29 - 34

Available online at http://jurnal.upmk.ac.id/index.php/lensapendas

\title{
EFEKTIVITAS MEDIA PEMBELAJARAN POP UP BOOK TERHADAP PENINGKATAN KEMAMPUAN MEMBACA SISWA SEKOLAH DASAR
}

\author{
Dessi Purnamasari ${ }^{1}$, Nana Sutarna ${ }^{2}$ \\ Pendidikan Guru Sekolah Dasar, STKIP Muhammadiyah Kuningan \\ nana@upmk.ac.id
}

\section{Info Artikel}

\section{Sejarah Artikel:}

Diterima Bulan Agustus, 2020

Dipublikasikan

September, 2020

\section{Keywords:}

\section{Media Pembelajaran \\ Pop Up Book, kemampuan membaca}

\section{Pop Up Book Learning Media, reading abilit}

\section{Abstrak}

Efektivitas Media Pembelajaran Pop Up Book Terhadap Peningkatan Kemampuan Membaca Siswa Sekolah Dasar Kelas II SDN Randobawailir, Pogram Studi Guru Sekolah Dasar (PGSD), 2019, Kemampuan Membaca anak perlu di tingkatkan, oleh karena itu pembelajaran harus menarik dan menyenangkan. Salah satu cara untuk meningkatkan kemampuan membaca adalah melalui buku cerita 3 dimensi. Penelitian ini bertujuan untuk mengetahui peningkatan kemampuan membaca adalah melalui buku cerita 3 dimensi (Pop Up Book). Penelitian ini merupakan tindakan kelas. Lokasi SDN Randobawailir Subyek dalam penelitian ini adalah anak didik Kelas II A dan II B SDN Randobawailir, semester II tahun pelajaran 2018/2019. Adapun jumlah anak didik kelas II A dan II B SDN Randobawailir adalah jumlah 44 anak. Data dikumpulkan melalui tes dan observasi. Keabsahan data diperiksa dengan perhitungan. Data dianalisis secara perhitungan kuantitatif media alur. Hasil penelitian ini menunjukan bahwa ada peningkatan dalam kemampuan membaca anak Sekolah Dasar melalui media pembelajaran 3 dimensi (Pop Up Book), yakni kemampuan membaca nilai rata-rata pretest sebesar 61,47 dan efektivitas media pembelajaran kemampuan membaca nilai rata-rata posttest sebesar 75,54, pengujian hipotesis dengan taraf signifikan 5\% ternyata thitung sebesar $\geq$ ttabel $(3.292$ $\geq 1,683$ ), maka HI diterima HO ditolak. Artinya terdapat peningkatan antara pretest dan posttest pada kelas eksperimen.

\section{Abstract}

The Effectiveness of Pop Up Book Learning Media Against the Improvement of Reading Ability of Elementary Class II SDN Randobawailir Students, Elementary School Teacher Study Program (PGSD), 2019, Children's Readingn Ability needs to be improved, therefore learning must be interesting and enjoyable. One way to improve reading skills is through 3-dimensional storybooks. This study aims to determine the increase in reading skills through 3-dimensional story books (Pop Up Book). This research is a class act. Randobawailir Elementary School Location The subjects in this study were students of Class II A and II B Randobawailir Elementary School, semester II of the 2018/2019 academic year. The number of students in class II A and IIB in Randobawailir Elementary School is 44 children. Data collected through tests and observations. Data validity is checked by calculation. Data were analyzed by quantitative calculation of flow media. The results of this study indicate that there is an increase in reading ability of elementary school children through 3-dimensional learning media (Pop Up Book), namely the ability to read an average pretest score of 61.47 and the effectiveness of learning media the ability to read a posttest average value of 75, 54, testing the hypothesis with a significant level of 5\% turns out to be t count of sebesar t table $(3,292 \geq 1,683)$, then HI is accepted Ho is rejected. This means that there is an increase between the pretest and posttest in the experimental class.

(C) 2020 Dessi Purnamasari ${ }^{1}$, Nana Sutarna ${ }^{2}$. Under the license CC BY-SA 4.0

Alamat Korespondensi Email

\author{
: STKIP Muhammadiyah Kuningan \\ : nana@upmk.ac.id
}

ISSN 2541-6855 (Online) ISSN 2541-0199 (Cetak) 


\section{PENDAHULUAN}

Pendidikan memiliki peran yang sangat penting bagi kehidupan manusia. Adanya pendidikan akan memberikan kontribusi yang besar dalam mempengaruhi perkembangan manusia dalam segala aspek kepribadian dan kehidupannya, sehingga akan tercipta kehidupan yang berkualitas dimasa yang akan datang.

$$
\text { Menurut Tatang }
$$

mengemukakan bahwa tujuan pendidikan adalah terwujudnya anak didik yang memahami ilmu yang diajarkan di dalam kelas dan di luar kelas, dan mengamalkannya dalam kehidupannya sehari-hari. Bagaimanapun bagus dan idealnya suatu strategi, maka strategi itu tidak mungkin bisa diaplikasikan. Keberhasilan implementasi suatu strategi pembelajaran akan tergantung pada kepiawaian guru dalam menggunakan metode, teknik, dan taktik pembelajaran. Namun pada kenyataanya belum baik dalam pembelajaran tidak menggunakan media, dan tidak sesuai harapan ini dengan dibuktikannya siswa kelas rendah yang masih belum baik dalam membaca.

Peneliti juga menemukan ada nya siswa kelas rendah yang masih belum baik dalam hal membaca di SDN Randobawa. Pada tanggal 10 februari saya mendatangi salah satu guru SDN Randobawa dan saya sekilas mewawancarai beliau tentang keseharian dalam proses belajar mengajar. Beliau mengatakan sedikit kerepotan dan bingung pada saat siswa ricuh dan tidak bisa dikondisikan pada saat proses pembelajaran berlangsung. Bahwa peran dan fungsi guru sangat berpengaruh terhadap pelaksanaan pendidikan di sekolah. Anak SD lebih suka terutama di kelas rendah menggunakan media unik dan peran guru sangat penting, memiliki keunikan dalam belajar disini guru akan sedikit kerepotan dalam proses belajar mengajar di kelas. (Fakta di Lapangan).

Menurut Susanto (2013:4) bahwa belajar adalah suatu aktivitas yang dilakukan seseorang dengan sengaja dalam keadaan sadar untuk memperoleh konsep, pemahaman, atau pengetahuan baru sehingga memungkinkan seseorang terjadinya perubahaan perilaku yang relatif tetapi baik dalam berpikir, merasa, maupun dalam bertindak.

Dalam pengajaran membaca cerita biasanya pendidik (guru) tidak secara langsung memberikan praktik di depan kelas. Proses pembelajaran ini adalah tentang kemampuan membaca di kelas rendah SDN Randobawa, beberapa siswa dalam kemampuan membaca ceritanya mengalami sedikit kesulitan, karena ada beberapa faktor penyebab terjadinya kurang baik dalam kemampuan membaca cerita di kelas rendah SDN Randobawa tersebut.

\section{METODE PENELITIAN}

Penelitian ini menggunakan pendekatan kuantitatif. Penelitian ini menggunakan metode penelitian eksperimen. Menurut Creswell (2013:5) penelitian kuantitatif merupakan metode-metode untuk menguji teori-teori tertentu dengan cara meneliti hubungan antar variabel. Variabel-variabel ini diukur biasanya dengan instrumen-instrumen penelitian sehingga data yang terdiri dari angkaangka dapat dianalisis berdasarkan prosedur-prosedur statistik.

Menurut Creswell (2013:19) penelitian eksperimen merupakan 
berusaha menentukan apakah suatu treatment mempengaruhi hasil sebuah penelitian. Pengaruh ini dinilai dengan cara menerapkan treatment tertentu pada satu kelompok (sering disebut kelompok treatment, penj) dan tidak menerapkannya pada kelompok yang lain (sering disebut kelompok kontrol, penj.), lalu menentukan bagaimana dua kelompok tersebut menentukan hasil akhir. (Eksperimental Research) yang bertujuan untuk menguji media Pop-Up book terhadap kemampuan membaca cerita siswa Sekolah Dasar. Variabel bebas pada penelitian ini adalah pengaruh media Pop-Up Book (X) sedangkan variabel terikatnya adalah kemampuan membaca cerita (Y).

\section{HASIL PENELITIAN DAN PEMBAHASAN}

1. Kemampuan membaca siswa kelas 2 SDN Randobawailir.

SDN Randobawailir masih rendah dalam kemampuan membaca terutama pada kelas rendah yaitu kelas II, dimana mayoritas dalam kemampuan membacanya masih rendah yang harus dilakukan tindakan kelas. Menurut beliau wali kelas II SDN Randobawailir ibu maspiah, S.Pd ada beberapa anak 1 sampai 2 diantaranya dalam membacanya ada yang masih terbata-bata. Hal ini dari semua pendidik ingin agar anakanak didiknya dalam hal membacanya masi rendah, hal ini sebabnya kurangnya penggunaan media pembelajaran. Siswa cepat bosan dan terlalu monoton dalam proses pembelajaran tersebut.

2. Penerapan media pembelajaran Pop Up Book pada siswa kelas 2 SDN Randobawaili

Pada tanggal 3 dan 4 mei 2019 dalam proses pembelajaran dikelas 2A SDN Randobawailir (Kelas Eksperimen) menggunakan media pembelajaran Pop Up Book siswa-siswa kelas 2 A sangat antusias dan sangking bersemangat siswa berlombalomba untuk membaca buku cerita lipetan potongan yang membentuk 3 dimensi menceritakan siang dan malam. Karena dalam proses pembelajaran tanggal 3 tersebut memfokuskan bahasa Indonesia dengan SBdP sedangkan tanggal 4 mei memfokuskan bahasa Indonesia dan matematika. setelah itu menyanyikan lagu cicak-cicak, lagu naik-naik puncak gunung, lagu kereta api, siswa intruksi melingkar berputar.

Peningkatan kemampuan membaca cerita siswa kelas 2 SDN Randobawailir dengan menggunakan media pembelajaran Pop Up Book. Berdasarkan perhitungan uji normalitas dengan menggunakan uji chi kuadrat posttest hasil belajar tema 7 kebersamaan siswa kelas II SDN Randobawailir setelah menerapkan media pembelajaran Pop Up diperoleh $\mathrm{X}^{2}$ hitung < $\mathrm{X}^{2}$ tabel $(-481<5,991)$ maka populasi penelitian berdistribusi normal.

Hasil perhitungan homogenitas diperoleh Fhitung < Ftabel 1,844982 < 2,210. Maka dapat disimpulkan hasil belajar siswa kelas eksperimen mempunyai variansi yang homogen. Hasil perhitungan N-Gain diperoleh nilai rata-rata gain pretest 61,47 , nilai rata-rata gain posttest 80,09 . Berdasarkan nilai rata-rata gain tersebut diperoleh nilai gain sebesar 33,52\% dengan peningkatan sebesar $18,62 \%$ termasuk kategori tinggi.

Berdasarkan perhitungan uji hipotesis secara statistik diperoleh nilai thitung $>$ ttabel (3,292>1,683) maka $\mathrm{H}_{1}$ yang diterima artinya terdapat peningkatan media pembelajaran Pop Up Book di tema 7 kebersamaan di kelas II SDN Randobawailir pada taraf signifikan $(\alpha)$ 0,05 .

Menurut Sholikhah (2017:1) berpendapat Pop Up Book merupakan buku yang menampilkan halaman-halaman buku yang di dalamnya terdapat lipatan gambar yang dipotong yang membentuk lapisan tiga dimensi yang dapat pula digerakkan sehingga tidak membosankan pembacanya. Media pembelajaran Pop Up Book disesuaikan dengan karakteristik 
perkembangan siswa SD yang memasuki tahap operasional konkret, dimana siswa mampu menghubungkan konsep-konsep baru dengan konsep-konsep lama. Analisis Data Yang digunakan dalam penelitian ini adalah tes pretest dan posttest di kelas kontol dan kelas eksperimen siswa kelas IIA/IIB SD Negeri Randobawailir sebelum menggunakan media pembelajaran Pop $U p$ Book, sesudah menggunakan media pembelajaran dan pembelajaran konvesional.

Tabel 4.9

Data Hasil Pretest Kelas Kontrol

\begin{tabular}{|c|c|c|c|}
\hline \multirow[b]{2}{*}{$\begin{array}{l}\mathbf{N} \\
\mathbf{0}\end{array}$} & \multicolumn{3}{|c|}{ Data Hasil Pretest } \\
\hline & $\begin{array}{c}\text { Kod } \\
\text { e } \\
\text { Sis } \\
\text { wa }\end{array}$ & $\begin{array}{c}\text { Jumla } \\
\text { h } \\
\text { Skor }\end{array}$ & Nilai \\
\hline 1 & KR & 15 & 68 \\
\hline 2 & LN & 17 & 77 \\
\hline 3 & MF & 12 & 54 \\
\hline 4 & MKI & 12 & 54 \\
\hline 5 & MKF & 15 & 68 \\
\hline 6 & MR & 16 & 72 \\
\hline 7 & MRS & 18 & 81 \\
\hline 8 & HBA & 17 & 77 \\
\hline 9 & $\mathrm{NE}$ & 18 & 81 \\
\hline 10 & PA & 14 & 63 \\
\hline 11 & $\mathrm{PN}$ & 13 & 59 \\
\hline 12 & RI & 14 & 63 \\
\hline 13 & RS & 13 & 59 \\
\hline
\end{tabular}

\begin{tabular}{|c|c|c|c|}
\hline \multirow{2}{*}{ No } & \multicolumn{3}{|c|}{ Data Hasil Pretest } \\
\cline { 2 - 4 } & Kode Siswa & Jumlah Skor & Nilai \\
\hline 14 & R & 13 & 59 \\
\hline 15 & REP & 14 & 63 \\
\hline 16 & RR & 15 & 68 \\
\hline 17 & SM & 17 & 77 \\
\hline 18 & IS & 17 & 77 \\
\hline 19 & SR & 14 & 63 \\
\hline 20 & VA & 18 & 81 \\
\hline 21 & VF & 15 & 68 \\
\hline 22 & YS & 16 & 72 \\
\hline \multicolumn{3}{|c|}{ Jumlah } & $\mathbf{1 5 1 3 , 1}$ \\
\hline \multicolumn{3}{|c|}{ Rata-rata } & $\mathbf{6 8 , 8 0}$ \\
\hline \multicolumn{3}{|c|}{ Terbesar } & $\mathbf{8 1}$ \\
\hline \multicolumn{3}{|c|}{ Terkecil } & $\mathbf{5 4}$ \\
\hline
\end{tabular}

Tabel 4.10

Data Hasil Posttest Kelas Kontrol

\begin{tabular}{|l|l|l|l|}
\hline \multirow{2}{*}{ No } & \multicolumn{3}{|l|}{ Data Hasil Posttest } \\
\cline { 2 - 4 } & $\begin{array}{l}\text { Kode } \\
\text { Siswa }\end{array}$ & $\begin{array}{l}\text { Jumlah } \\
\text { Skor }\end{array}$ & Nilai \\
\hline 1 & KR & 18 & 90 \\
\hline 2 & LN & 20 & 90 \\
\hline 3 & MF & 9 & 40 \\
\hline 4 & MKI & 18 & 81 \\
\hline 5 & MKF & 17 & 77 \\
\hline 6 & MR & 18 & 81 \\
\hline 7 & MRS & 19 & 86 \\
\hline 8 & MBA & 18 & 81 \\
\hline 9 & NE & 15 & 68 \\
\hline 10 & PA & 16 & 72 \\
\hline 11 & PN & 15 & 68 \\
\hline 12 & RI & 12 & 54 \\
\hline 13 & RS & 10 & 45 \\
\hline
\end{tabular}

\begin{tabular}{|c|c|c|c|}
\hline \multirow{2}{*}{ No } & \multicolumn{3}{|c|}{ Data Hasil Posttest } \\
\cline { 2 - 4 } & $\begin{array}{c}\text { Kode } \\
\text { Siswa }\end{array}$ & $\begin{array}{c}\text { Jumlah } \\
\text { Skor }\end{array}$ & Nilai \\
\hline 14 & R & 17 & 77 \\
\hline 15 & REP & 20 & 90 \\
\hline 16 & RR & 18 & 81 \\
\hline 17 & SM & 20 & 90 \\
\hline 18 & IS & 13 & 59 \\
\hline 19 & SR & 14 & 63 \\
\hline 20 & VA & 20 & 90 \\
\hline 21 & VF & 17 & 77 \\
\hline
\end{tabular}


Jurnal Lensa Pendas, Vol. 5 Nomor 2 Tahun 2020, HIm 29 - 34

Dessi Purnamasari ${ }^{1}$, Nana Sutarna ${ }^{2}$

\begin{tabular}{|c|c|c|c|}
\hline \multirow{2}{*}{ No } & \multicolumn{3}{|c|}{ Data Hasil Posttest } \\
\cline { 2 - 4 } & $\begin{array}{c}\text { Kode } \\
\text { Siswa }\end{array}$ & $\begin{array}{c}\text { Jumlah } \\
\text { Skor }\end{array}$ & Nilai \\
\hline 22 & YS & 14 & 63 \\
\hline \multicolumn{3}{|c|}{ Jumlah } & $\mathbf{1 6 2 7 , 2 7}$ \\
\hline \multicolumn{3}{|c|}{ Rata-rata } & $\mathbf{7 3 , 9 7}$ \\
\hline \multicolumn{3}{|c|}{ Terbesar } & $\mathbf{9 0}$ \\
\hline \multicolumn{3}{|c|}{ Terkecil } & $\mathbf{4 0}$ \\
\hline
\end{tabular}

Tabel 4.11

Data Hasil Pretest Kelas Eksperimen

\begin{tabular}{|c|l|c|c|}
\hline \multirow{2}{*}{ No } & \multicolumn{3}{|c|}{ Data Hasil Pretest } \\
\cline { 2 - 4 } & $\begin{array}{c}\text { Kode } \\
\text { Sisw } \\
\text { a }\end{array}$ & $\begin{array}{c}\text { Jumlah } \\
\text { Skor }\end{array}$ & Nilai \\
\hline 1 & ARF & 17 & 77 \\
\hline 2 & ASC & 11 & 50 \\
\hline 3 & AR & 9 & 40 \\
\hline 4 & APS & 18 & 81 \\
\hline 5 & AZ & 18 & 81 \\
\hline 6 & AR & 9 & 40 \\
\hline 7 & AP & 15 & 68 \\
\hline 8 & AR & 16 & 72 \\
\hline 9 & AP & 10 & 45 \\
\hline 10 & BA & 13 & 59 \\
\hline 11 & CA & 11 & 50 \\
\hline 12 & DY & 12 & 54 \\
\hline 13 & DA & 15 & 68 \\
\hline
\end{tabular}

\begin{tabular}{|c|c|c|c|}
\hline \multirow[b]{2}{*}{ No } & \multicolumn{3}{|c|}{ Data Hasil Pretest } \\
\hline & $\begin{array}{l}\text { Kode } \\
\text { Siswa }\end{array}$ & $\begin{array}{c}\text { Jumlah } \\
\text { Skor }\end{array}$ & Nilai \\
\hline 14 & ES & 12 & 54 \\
\hline 15 & FM & 15 & 68 \\
\hline 16 & FW & 12 & 54 \\
\hline 17 & $\mathrm{HL}$ & 12 & 54 \\
\hline 18 & IS & 13 & 59 \\
\hline 19 & IS & 10 & 45 \\
\hline 20 & SS & 21 & 95 \\
\hline 21 & JS & 15 & 68 \\
\hline \multicolumn{3}{|c|}{ Jumlah } & 1290,9 \\
\hline \multicolumn{3}{|c|}{ Rata-rata } & 61,47 \\
\hline \multicolumn{3}{|c|}{ Terbesar } & 95 \\
\hline \multicolumn{3}{|c|}{ Terkecil } & 40 \\
\hline
\end{tabular}

\begin{tabular}{|c|c|c|c|}
\hline \multirow{2}{*}{ No } & \multicolumn{3}{|c|}{ Data Hasil Posttest } \\
\cline { 2 - 4 } & $\begin{array}{c}\text { Kode } \\
\text { Siswa }\end{array}$ & $\begin{array}{c}\text { Jumlah } \\
\text { Skor }\end{array}$ & Nilai \\
\hline 14 & 19 & 86 & 19 \\
\hline 15 & 16 & 72 & 16 \\
\hline 16 & 18 & 81 & 18 \\
\hline 17 & 16 & 72 & 16 \\
\hline 18 & 18 & 81 & 18 \\
\hline 19 & 18 & 81 & 18 \\
\hline 20 & 18 & 81 & 18 \\
\hline 21 & 22 & 100 & 22 \\
\hline \multicolumn{3}{|c|}{ Jumlah } & $\mathbf{1 5 8 6 , 4}$ \\
\hline \multicolumn{3}{|c|}{ Tata-rata } & $\mathbf{7 5 , 5 4}$ \\
\hline \multicolumn{3}{|c|}{ Terkesar } & $\mathbf{1 0 0}$ \\
\hline \multicolumn{4}{|c|}{} \\
\hline
\end{tabular}

Tabel 4.12

Data Hasil Posttest Kelas Eksperimen 
Tabel 4.13

Data Hasil Pretest dan Posttest Kelas Eksperimen dan Kelas Kontrol

1.Uji Normalitas

\section{Pretest}

\begin{tabular}{|l|l|l|}
\hline Kelas & Eksperimen & Kontrol \\
\hline$x^{2}$ hitung & $-44,55$ & $-6,16$ \\
\hline Dk & 2 & 2 \\
\hline$x^{2}$ tabel $(95 \%)$ & 5,991 & 5,991 \\
\hline Kriteria & Normal & Normal \\
\hline
\end{tabular}

\section{Posttest}

\begin{tabular}{|l|l|l|}
\hline Kelas & Eksperimen & Kontrol \\
\hline$x^{2}$ hitung & $-4,81$ & $-6,16$ \\
\hline Dk & 2 & 2 \\
\hline$x^{2}$ tabel $(95 \%)$ & 5,991 & 5,991 \\
\hline Kriteria & Normal & Normal \\
\hline
\end{tabular}

Tabel 4.14

Data Hasil N-Gain Kelas Eksperimen Dan

\section{Kontrol}

\begin{tabular}{|l|l|l|}
\hline Kelas & Eksperimen & Kontrol \\
\hline$x^{2}$ hitung & $-80,03$ & $-16,26$ \\
\hline Dk & 2 & 2 \\
\hline$x^{2}$ tabel $(95 \%)$ & 5,991 & 5,991 \\
\hline Kriteria & Normal & Normal \\
\hline
\end{tabular}

1. Uji Homogenitas

Tabel 4.15

Data Hasil Uji N-Gain

\begin{tabular}{|l|l|l|l|}
\hline \multirow{2}{*}{ Kelas } & \multicolumn{2}{|c|}{ Nilai Rata-rata } & \multirow{2}{*}{ Gain } \\
\cline { 2 - 3 } & Pretest & Posttest & \\
\hline Eksperimen & 61,47 & 80,09 & $33,52 \%$ \\
\hline Kontrol & 68,80 & 73,97 & $15,51 \%$ \\
\hline
\end{tabular}

Tabel 4.16

Data Hasil Uji N-Gain Peningkatan

\begin{tabular}{|l|l|l|l|}
\hline \multirow{2}{*}{ Kelas } & \multicolumn{2}{|l|}{ Nilai Rata-rata } & \multirow{2}{*}{ Peningkatan } \\
\cline { 2 - 3 } & Pretest & Posttest & \\
\hline Eksperimen & 61,47 & 80,09 & 18,62 \\
\hline
\end{tabular}

\begin{tabular}{|l|l|l|l|}
\hline \multirow{2}{*}{ Kelas } & \multicolumn{2}{|c|}{ Nilai Rata-rata } & \multirow{2}{*}{ Peningkatan } \\
\cline { 2 - 3 } & Pretest & Posttest & \\
\hline Kontrol & 68,80 & 73,97 & 5,67 \\
\hline
\end{tabular}

Tabel 4.17

Data Hasil Uji Hipotesis

\begin{tabular}{|l|l|l|}
\hline Data & Kelas Kontrol & Kelas Eksperimen \\
\hline Jumlah sampel (n) & 22 & 21 \\
\hline Standar deviasi (S) & 16,87 & 12,42 \\
\hline Standar Deviasi Gabungan & 14,65 & 75,71 \\
\hline Rata-rata & 58,27 & \\
\hline Thitung & 3,292 \\
\hline ttabel & 1,683 \\
\hline Kesimpulan & \multicolumn{2}{|l}{. diterima, $\mathrm{H}_{0}$ ditolak } \\
\hline
\end{tabular}

\section{SIMPULAN}

Berdasarkan hasil penelitian dan pembahasan Efektivitas Media Pembelajaran Pop Up Book Terdapat Peningkatan Kemampuan Membaca Siswa SDN Randobawailir, maka penulis menarik kesimpulan sebagai Berikut :

1. Kemampuan membaca siswa kelas 2 SDN Randobawailir Pada kenyataannya di SDN Randobawailir masih rendah dalam kemampuan membaca terutama pada kelas rendah yaitu kelas II, dimana mayoritas dalam kemampuan membacanya masih rendah yang harus dilakukan tindakan kelas. Menurut beliau wali kelas II SDN Randobawailir ibu maspiah, S.Pd ada beberapa anak 1 sampai 2 diantaranya dalam membacanya ada yang masih rendah.

2. Penerapan media pembelajaran Pop Up Book pada siswa kelas 2 SDN Randobawailir Pada tanggal 3 dan 4 mei 2019 dalam proses pembelajaran dikelas 2A SDN Randobawailir (Kelas Eksperimen) menggunakan media pembelajaran Pop Up Book siswasiswa kelas 2 A sangat antusias dan sangking bersemangat siswa berlombalomba untuk membaca buku cerita lipetan potongan yang membentuk 3 dimensi menceritakan siang dan malam.

3. Terdapat peningkatan Media Pembelajaran Pop Up Book terhadap kemampuan membaca siswa kelas 2 SDN Randobawailir. Terhadap Peningkatan Kemampuan Membaca pada tema 7 kebersamaan subtema 1 kebersamaan keluarga di SDN Randobawailir kelas II pada taraf signifikan $(\alpha) 0,05$. Hal ini dibuktikan dari perhitungan secara statistik diperoleh nilai hipotesis 3,292>1,683 maka $\mathrm{H}_{1}$ yang diterima. 


\section{DAFTAR PUSTAKA (12PT)}

Creswell, Jhon W. 2013. Research Desaign Pendekatan Kualitatif, Kuantitatif, dan Mixed, Yogyakarta : Pustaka Belajar.

Tatang. 2012. Ilmu Pendidikan. Bandung : CV Pustaka Setia.

Susanto, Ahmad. 2013 Teori Belajar dan Pembelajaran di Sekolah Dasar. Jakarta : Prenadamedia Group.

Sholikhah, Aimatus. 2017. Pengembangan Media Pop Up Book Untuk Meningkatkan Kemampuan Menulis Kreatif Pada Mata Pelajaran Bahasa Indonesia Materi Menulis Karangan Kelas V SDN di Rowoharjo. Jurnal Univesitas Nusantara PGRI SimkiPedagogia Vol. 01 No. 08 tahun 2017 ISSN : 2599-073X 
Jurnal Lensa Pendas, Vol. 5 Nomor 2 Tahun 2020, HIm 29 - 34

Dessi Purnamasari ${ }^{1}$, Nana Sutarna ${ }^{2}$ 